\title{
REVIEW
}

\section{Plexiform Arteriopathy in Rodent Models of Pulmonary Arterial Hypertension}

\author{
Brandon L. Carman, ${ }^{*}$ Dan N. Predescu, ${ }^{*}$ Roberto Machado, ${ }^{\dagger}$ and Sanda A. Predescu*
}

From the Division of Pulmonary Critical Care and Sleep Medicine, * Department of Internal Medicine, Rush Medical College, Chicago, Illinois; and the Division of Pulmonary, Critical Care, Sleep, and Occupational Medicine, ${ }^{\dagger}$ Department of Medicine, Indiana University, Indianapolis, Indiana

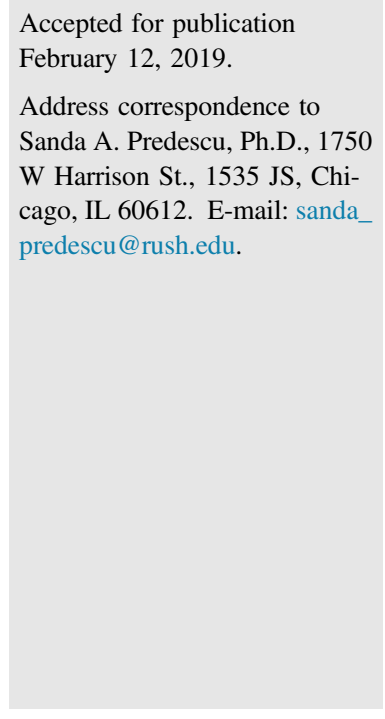

Accepted for publication

ebruary $12,2019$.

Sanda A. Predescu, Ph.D., 1750

W Harrison St., 1535 JS, Chicago, IL 60612. E-mail: sanda predescu@rush.edu.

As reviewed recently, there are inherent limitations in animal models. ${ }^{1}$ These limitations, particularly the inability to predict translational therapeutic efficacy from an animal model to humans, may stem from shortfalls in defining the precise mechanisms that promote human disease-like phenotypes in animal models. Therefore, more time must be dedicated to discern key differences in the pathogenic mechanisms that promote the same disease in different animal models. In other words, efforts should be made to understand how different stimuli produce the same disease. In turn, small molecular players, once overshadowed by general association, might start to be teased out of the ever-complex cellular network, thereby shedding light on key divergences in disease pathogenesis. Ideally, these divergences will translate into the clinic through efforts of personalized patient care. Of course, this requires our understanding of the human pathology to proceed in a similar manner. However, we, as a global scientific community, often find ourselves in a harsh reality: brief excitement regarding a promising therapeutic agent, followed by translational turmoil and eventual letdown in the clinic. This harsh reality especially pertains to pulmonary arterial hypertension (PAH). Driven by the grim statistical nature of 5-year survival rates of $57 \%$ in PAH patients, ${ }^{2}$ this review will attempt to stimulate translatable research to raise morale for both physicians and patients. The review outlines the different animal models used in PAH studies, while retaining a strong focus on their relatability to human patients. It further advances the way in which we use animal models of the same disease to improve our overall understanding of the multifaceted disease, such as PAH.

Supported by NIH/National Heart, Lung, and Blood Institute grant R01 HL127022 (S.A.P.).

Disclosures: None declared. 
Idiopathic PAH is a complex and deadly disease, characterized by dysfunctional, hyperproliferative, and apoptosisresistant pulmonary endothelial cells (ECs) that govern a pathologic state of persistent pulmonary inflammation and the dysregulation of both pulmonary smooth muscle cells and fibroblasts. ${ }^{3,4}$ This unusual cellular behavior results in progressive, obliterative remodeling of small- to mid-sized pulmonary vessels, leading to increased vascular resistance, right ventricular hypertrophy $(\mathrm{RVH})$, right-sided heart failure, and early death. ${ }^{5}$ Furthermore, histologic staining of lung tissue from patients with advanced PAH shows occlusive plexiform lesions (PLs) and muscularized vessels that obliterate the small- to midsized pulmonary arterioles. ${ }^{4}$ Despite significant leaps in our understanding of PAH and its associated mechanisms, state-ofthe-art therapeutics still fail to target the ongoing remodeling process. Instead, current therapies only remedy PAH through manipulation of vasoactive signaling pathways involved in maintenance of vascular tone. ${ }^{6}$ As a result, 5-year survival rates remain unacceptably low, at $57 \% .^{2,5,7}$ These low survival rates stem from our inability to translate therapeutic benefits from $\mathrm{PAH}$ animal models to humans. Therefore, it is time to transition from a classic view to a more holistic approach that encompasses not only animal models and the interworking of their precise mechanisms, but also retains focus on the human phenotype.

\section{Classic Animal Models of PAH}

Before exploring the various animal models used to study PAH, it is important to note that this review will use pulmonary hypertension and $\mathrm{PAH}$ almost interchangeably because the classic models used to study PAH are more representative of pulmonary hypertension pathology. Currently, it is accepted that two distinct phases exist in the pathogenesis of PAH. The first phase, or nonspecific medial and adventitial thickening of the pulmonary artery ${ }^{8}$ is well reproduced in the classic animal models [ie, hypoxia-induced pulmonary hypertension and monocrotaline (MCT)-induced pulmonary hypertension]. However, the second phase, or the progressive, plexogenic arteriopathy phase of $\mathrm{PAH},{ }^{8}$ is absent in these models. In other words, the classic models fail to induce aberrant EC proliferation that results in PLs. These PLs result in vessel lumen obliteration and, therefore, disrupt efficient gas-nutrient exchange in the lung. Nevertheless, because of the lack of better means, past PAH studies were commonly performed in hypoxia-induced pulmonary hypertension and MCT lung injury models. Because the rodents (ie, mice and rats) were typically the species of choice for induction of pulmonary hypertension in these models, they will be the central focus of this review.

\section{Hypoxia-Induced Pulmonary Hypertension}

The groundwork for PAH-based studies comes from past results that suggested acute hypoxic insult results in pulmonary vasoconstriction. ${ }^{9}$ It was demonstrated in the same study that the pulmonary vasculature of distinct species responds uniquely when challenged with an acute hypoxic stress, and, thus, they were classified as responders or nonresponders. ${ }^{9}$ Years later, data supported that, not only do acute and chronic hypoxic stresses differentially affect distinct species, but they also induce unique responses in different strains of the same species (ie, Sprague-Dawley versus Fischer 344 rats). ${ }^{10}$ Another example of this bizarre modulation is found in a study that showed fawn-hooded rats develop spontaneous and severe pulmonary hypertension that is accelerated by hypoxic challenge when compared with Sprague-Dawley rats. ${ }^{11}$ Extending our knowledge of these concepts, with use of modern technology, was Hoshikawa et al, ${ }^{12}$ who demonstrated that C57BL/6 mice and Sprague-Dawley rats, challenged by acute and chronic hypoxic stresses, exhibited significant differences in gene expression profiles. These differences resulted in a more severe phenotype in SpragueDawley rats versus C5BL/6 mice (ie, higher pulmonary artery pressures and higher vessel wall thickness). ${ }^{12}$ The aforementioned studies apply directly to the human organism. In other words, studies have demonstrated that humans are also differentially affected by chronic hypoxic stress because of high altitude. ${ }^{13}$ This is apparent in studies that showed the high-altitude Tibetan population-living on the Tibetan Plateau-is protected against hypoxia-induced pulmonary hypertension, whereas the Andean and Ethiopian populations - also living at high altitude - are not. ${ }^{14}$ Paralleling hypoxia-induced pulmonary hypertension in rodents, genetic adaptation in humans seems to account for the disparate responses to hypoxic stress. Specifically, numerous studies have repeatedly shown that the Tibetan population exhibits genetic modulation of the prolyl hydroxylase domain protein 2 (PHD2)/hypoxia-inducible factor $2 \alpha$ (HIF-2 $\alpha$ ) signaling axis when compared with the Ethiopian and Andean populations, and this genetic modulation results in protection against hypoxia-induced pulmonary hypertension: it is unknown if this genetic modulation is attributable to gain or loss of function. ${ }^{14}$ Supporting evidence implicating the PHD2/ HIF- $2 \alpha$ axis in PAH comes from a genetic mouse model designed to mimic the human PAH phenotype. In this mouse model, endothelial- and hematopoietic cell-specific genetic ablation of $E g \ln 1$ (encoding PHD2) resulted in spontaneous and severe PAH. ${ }^{15}$ Moreover, when both $E g \ln l$ and $H I F-2 \alpha$ genes were disrupted in endothelial and hematopoietic cells, these mice did not develop PAH. ${ }^{15}$ These data open new avenues for the classic, hypoxic stress-induced pulmonary hypertension rodent models.

\section{New Potential for Classic Hypoxia-Induced Pulmonary Hypertension}

Current hypoxia-induced pulmonary hypertension rodent models are not suitable preclinical models for studying PAH pathology. This is particularly attributable to the lack of key pathologic features observed in human PAH: angio-obliterative 
PLs, neointima proliferation, and mononuclear cell infiltration. Because species and different strains of the same species differ in response when challenged by hypoxic stress, it seems unlikely that there is one simple solution to treating hypoxiainduced pulmonary hypertension (or PAH). However, when examining the findings of the study by Dai et $\mathrm{al}^{15}$ and the data regarding the human body's response to high-altitude-induced hypoxia side by side, the data strongly suggest that the Tibetan population is able to combat hypoxic stress because of genetic adaptation, resulting in gain-of-function hydroxylase capability of PHD2 and/or loss-of-function HIF-2 $\alpha$ signaling. However, this has yet to be confirmed. Moreover, the $E g \ln 1^{-/-}$mouse model directly targeted a pathway that is implicated in highaltitude hypoxia-induced pulmonary hypertension in humans, but yet resulted in a PAH phenotype. Genetic comparison, using the gene expression data collected from previously published studies on the Tibetan, Ethiopian, and Andean populations compared with the gene expression data collected from the $E g \ln 1^{-1-}$ mouse model of PAH, may elucidate a novel signaling network responsible for the progressive, obliterative pulmonary remodeling ${ }^{14}$; this is observed in PAH patients versus the much more mild phenotype, as seen in hypoxiainduced pulmonary hypertension. Furthermore, as mentioned by Grover, ${ }^{9}$ certain species or strains of a species are nonresponders and are protected against acute and chronic hypoxic stress, but, to our knowledge, the status of PHD2/HIF- $2 \alpha$ in these animals (ie, sheep or Fischer rats) has yet to be investigated. An investigation of the PHD2/HIF-2 $\alpha$ signaling axis in these resistant animals could provide strong evidence for the protective, or not so protective, roles of PHD2 and HIF- $2 \alpha$ in hypoxia-induced pulmonary hypertension. Despite a promising potential, these genomic studies have not yet been performed. In addition to hypoxia-induced pulmonary hypertension, another classic animal model used to study PAH is the MCT lung injury model.

\section{MCT-Induced Pulmonary Hypertension}

MCT is a plant-derived compound, and when it is consumed, it induces hepatotoxicity and pulmonary hypertension in humans. ${ }^{16}$ To investigate the mechanism of MCT-induced pulmonary hypertension in humans, a single dose of MCT ( 60 to $80 \mathrm{mg} / \mathrm{kg}$ ) is injected subcutaneously in rats to induce pulmonary hypertension - a mechanism dependent on conversion of MCT to MCT pyrrole by the cytochrome P450 system in the liver (specifically, cytochrome P450 3A4). ${ }^{16-18}$ Contrary to rats, a single dose of MCT does not induce severe pulmonary hypertension in mice; in attempts to explain these findings, researchers suggested a simplistic hypothesis that mice metabolize MCT differently from other species. ${ }^{19,20}$ However, a single injection of bioactive MCT pyrrole into mice failed to reproduce the MCT-induced pulmonary hypertension phenotype, as previously observed. ${ }^{21}$ These data suggest the lack of MCT syndrome in mice is not attributable to metabolic restraints but to some alternative mechanism.
Intriguingly, a different group investigated the effects of administering a higher dose of MCT (300 and $600 \mathrm{mg} / \mathrm{kg}$ ) weekly to mice for 8 weeks, and this group demonstrated that mice developed MCT-induced pulmonary hypertension. ${ }^{22}$ It is unclear why a higher, repeated weekly dose is required to induce PAH in mice, but is not necessary in rats. Nevertheless, the suitability of MCT-induced pulmonary hypertension rodent models in the study of PAH remains questionable.

Previous studies demonstrated that MCT administration in rats results in severe pneumotoxicity. ${ }^{23,24}$ This pneumotoxicity is also referred to as MCT syndrome. MCT syndrome is mainly characterized by pulmonary hypertension driven by increases in pulmonary artery medial and adventitial thickening, muscularized smaller pulmonary arteries, pruning of the peripheral pulmonary arteries, and $\mathrm{RVH}^{24,25}$ Each of these consequences of MCT administration is evident in human PAH patients; however, MCT injury is not unique to the pulmonary artery, and also results in alveolar edema, alveolar septal cell hyperplasia, myocarditis, hepatic veno-occlusive disease, and renal insufficiency. ${ }^{17}$ Although PAH has numerous etiologies, common histologic findings suggest PAH-associated pathology favors remodeling of the small- to medium-sized pulmonary arteries $(20$ to $150 \mu \mathrm{m}){ }^{26}$ Contrary to PAH, MCT-induced pulmonary hypertension has widespread action, affecting multiple organ systems, along with a broad pneumotoxicity, rather than localized events affecting smallto medium-sized vessels. Therefore, results using the MCT rodent model to study PAH may be compromised by unforeseen confounding interactions associated with the widespread action of MCT. Furthermore, similar to chronic hypoxia rodent models, MCT administration does not result in PLs, as observed in the human phenotype of PAH. ${ }^{27}$ Hence, as our understanding of the pathobiology of PAH progresses, the shortcomings of the classic models of pulmonary hypertension (ie, chronic hypoxia and MCT) become clearer. As a result, new genetic and two-hit rodent models that recapitulate many aspects of the human phenotype were developed, and they are now emerging as the favored experimental animal models to study PAH pathobiology. The potential of two-hit models was demonstrated by Morimatsu et al, ${ }^{28}$ who showed that treating rats with MCT and hypoxia simultaneously induced the development of plexiform-like lesions, a common histologic feature of PAH pathology that is absent in the classic hypoxia and MCT animal models. Another two-hit model, based on the classic MCT-treated rats, is the pneumonectomy + MCT rat model. This procedure requires surgical pneumonectomy, followed by a 1-week recovery period, during which the rats are given a single dose of MCT. ${ }^{29}$ The resultant phenotype is severe, characterized by neointima and smooth muscle hypertrophy in the small- and medium-sized pulmonary vessels. Moreover, these rats undergo vascular pruning and develop complex plexiform-like lesions containing EC slit-like channels; this aforementioned lung phenotype culminates to elevated right 
ventricular systolic pressure (RVSP) and RVH measurements. Although invasive, this animal model recapitulates many aspects of human $\mathrm{PAH}^{29}$

\section{Su-Hx Rodent Model}

Sugen5416 (Su5416) is an exogenous compound that inhibits vascular endothelial growth factor receptor protein tyrosine kinase 1/2 (VEGFR1/2), and when administered to rats in conjunction with chronic hypobaric hypoxia ( $\mathrm{Su}-\mathrm{Hx})$, a severe pulmonary hypertension phenotype develops. ${ }^{30}$ Noticing the potential of the Su-Hx rat model, Abe et $\mathrm{al}^{31}$ took the Su-Hx model one step further, and after a single injection of Su5416 and 3 weeks of hypobaric hypoxia, the rats were returned to normoxia for 10 to 11 weeks $(\mathrm{Su}-\mathrm{Hx}$ $\mathrm{Nx}$ ). In addition to the severe pulmonary hypertension phenotype, driven by $\mathrm{Su}-\mathrm{Hx}$, reoxygenation for 10 weeks results in the formation of severe PLs: concentric neointimal and complex plexiform-like lesions. ${ }^{31}$ The characterization of this rat model made it clear that it closely mimics human plexogenic arteriopathy observed in PAH. After this study, an explanation of how inhibition of the prosurvival VEGFR1/2 signaling cascade could promote aberrant EC proliferation was needed: it has been suggested that uninhibited VEGFR3 could be the predominant signaling pathway driving EC proliferation. ${ }^{32}$ An alternative explanation could be that the VEGFR signaling cascade provides survival queues for pulmonary ECs; inhibition by Su5416 would then promote EC apoptosis, hence stimulating precapillary vascular pruning. ${ }^{33}$ This initial EC apoptotic event could provide an opportunistic window in which an EC selection process can occur. Further facilitating the EC selection process is the second hit of hypoxic stress. This two-hit process could result in the emergence of ECs that do not require VEGFR1/2 signaling to live and, hence, are apoptosis-resistant ECs to this particular apoptosis signaling cascade (caspase-dependent apoptosis). ${ }^{30}$ In theory, these cells would then thrive off the organelle- and nutrientenriched apoptotic bodies released from the apoptosissensitive ECs, resulting in aberrant EC proliferation and further propagation of apoptosis-resistant ECs: it is possible that ECs first go into senescence, followed by hyperproliferative potential. On returning the $\mathrm{Su}-\mathrm{Hx}$ rats to normoxia, the emergent EC population, although once underrepresented, is now the dominant EC phenotype, thriving in the stress-free environment, and may result in the progressive development of neointimal and complex plexiform-like lesions in the rat lung. This process provides strong support for the EC monoclonal selection theory, exhibited in humans afflicted by primary pulmonary hypertension. ${ }^{34} \mathrm{Su}-\mathrm{Hx}-\mathrm{Nx}$ mice, treated with a similar regimen as Su-Hx-Nx rats, do not develop extensive angioobliterative, concentric neointimal lesions or complex plexiform-like lesions. ${ }^{35}$ This fact argues against the aforementioned selection process that occurs in the rat model.
However, as demonstrated earlier, rats and mice exhibit differential gene regulation in response to hypoxic stress, ${ }^{12}$ and, thus, these differences may protect against the expansion of a monoclonal EC population that drives plexogenic arteriopathy. Nevertheless, the Su-Hx-Nx rat model is among one of the strongest preclinical rodent models used to study PAH because of its extremely severe phenotype. Although successful in rats, this model did not address the demand for a preclinical mouse model that closely resembles the human PAH phenotype.

\section{The Search for a Mouse Model of Plexogenic Arteriopathy}

\section{IL-6-0verexpressing Mice}

In search of a mouse model that develops a severe phenotype and successfully recapitulates the human PAH phenotype, Steiner et $\mathrm{al}^{36}$ relied on the basis that PAH pathophysiology may rely on inflammatory mediators. The role of these perivascular inflammatory cell infiltrators in PAH has previously been implicated ${ }^{37-39}$ and, thereby, led to the development of IL-6-overexpressing transgenic (IL-6 $\mathrm{Tg}^{+}$) mice. ${ }^{36}$ Other ILs, such as IL-8, IL-12, IL-20, and IL-33, have also been implicated in PAH. ${ }^{3,4}$ IL-6 signals through two unique pathways for its biological effects: the cis and trans signaling pathways, both of which are implicated in $\mathrm{PAH} .{ }^{40}$ Each signaling mechanism results in the up-regulation of STAT3, extracellular signalregulated kinase $1 / 2$, mitogen-activated protein kinase (MAPK), AKT, and phosphatidylinositol 3-kinase signaling and the up-regulation of antiapoptotic factors, such as survivin, VEGF, and B-cell lymphoma 2 (BCL-2). ${ }^{40}$ With enough dysregulation of the IL-6 signaling pathway, these factors may converge and promote aberrant proliferation and an antiapoptotic phenotype in ECs, smooth muscle cells, and fibroblasts, as observed in PAH. The IL- $6 \mathrm{Tg}^{+}$mouse model promotes this exact phenotype. The IL- $6 \mathrm{Tg}^{+}$mice exhibit several key pathologic features of human $\mathrm{PAH}$ : distal extension of smooth muscle into the small pulmonary arteries; hyperproliferative ECs, leading to concentric intimal wall thickening; and mild plexiform-like lesions, RVH, and increases in RVSP. Intriguingly, when IL- $6 \mathrm{Tg}^{+}$mice are exposed to hypoxic stress, all observed pathologic phenotypes are exacerbated. ${ }^{36}$ Moreover, IL-6 $\mathrm{Tg}^{+}$mice exhibit increases in medial wall thickness of both the main and bronchial pulmonary arteries and an increased number in elastic lamellar layers. ${ }^{36}$ However, muscularization of the main and bronchial pulmonary arteries is typically unaltered in PAH and is, rather, characterized by a vasoconstrictive state. ${ }^{41}$ These off-targeted findings suggest that elevated levels of IL- 6 in the serum and lungs of PAH patients may be a result of the initial onset of the disease rather than the cause. Nevertheless, by identifying key molecular players partaking in the cross talk between ECs, smooth muscle cells, and inflammatory cells, the IL- $6 \mathrm{Tg}^{+}$mouse model has significantly advanced our understanding of the pathologic processes driving PAH. ${ }^{36}$ Furthermore, to our knowledge, this 
was the first model to develop robust plexiform-like lesions in mice, whereas prior studies had failed to induce plexogenic arteriopathy in mice with a high success rate. ${ }^{42}$ Despite capturing the main pathologic features associated with $\mathrm{PAH}$, the severity of the PLs in the IL- $6 \mathrm{Tg}^{+}$mice remains questionable. As a result, a demand to generate a mouse model with a more severe phenotype remained.

\section{Egln1 Knockout Mice}

Answering the calls for a more severe $\mathrm{PAH}$ phenotype in mice was a study that generated a mouse model with EC- and hematopoietic cell-specific genetic ablation of $E g \ln 1$-a gene encoding the protein PHD2. ${ }^{15}$ As previously mentioned, in the high altitude of the Tibetan population, there is apparent genetic manipulation of the PHD2/HIF- $2 \alpha$ signaling axis, and these genetic adaptations protect against high altitude-induced pulmonary hypertension. ${ }^{14}$ Along these lines, EC- and hematopoietic cell-specific $E g \ln 1^{-l-}$ mice exhibited a progressive, severe PAH phenotype by 3.5 months of age. ${ }^{15}$ Hemodynamic studies, characterizing the phenotype in these mice, showed significant increases in RVSP, up to $90 \mathrm{mmHg}$, RVH, and decreased contractility. Moreover, similar to the clinic, these mice exhibited progressive right ventricular dysfunction, as approximately $80 \%$ of the mice died by 6 months of age. ${ }^{15}$ Consistent with the hemodynamic studies, $E g \ln 1^{-1-}$ mice present significant obliterative pulmonary artery remodeling: intima, medial, and adventitial thickening and the presence of occlusive and plexiform-like lesions. It is worth recognizing that the angioobliterative, plexiform-like, and occlusive lesions exhibited in this transgenic mouse are much more severe in comparison to those in IL-6 $\mathrm{Tg}^{+}$mice. ${ }^{36}$ Moreover, the observed pulmonary phenotype, particularly the associated plexiform arteriopathy, is attributed to HIF- $2 \alpha$ activation, resulting from PHD2 deficiency. Intriguingly, endothelial-specific PHD2 deficiency, but not hematopoietic cell-specific deficiency, is required for PAH onset, whereas PHD2 deficiency in hematopoietic cells inversely modulates severity of the phenotype. ${ }^{15}$ Further speculation leads us to believe that perhaps the hematopoietic cells shed PHD2-bearing microparticles that act on PHD2-deficient ECs. This interaction could rescue the aberrant phenotype, thereby improving the overall severity of the disease; this mechanism was previously demonstrated in other types of lung disease. ${ }^{43,44}$ Although not tested, if true, administering PHD2-containing microparticles of hematopoietic cell origin may prove efficacious in treating idiopathic PAH patients. Regardless, this is the first study, to our knowledge, to generate a severe mouse model of PAH that recapitulates almost all key pathologic features exhibited in the human PAH phenotypes. Furthermore, this study provides insight on how genetic adaptation to the PHD2/HIF- $2 \alpha$ signaling axis protects the Tibetan population from highaltitude, hypoxia-induced pulmonary hypertension (ie, PHD2 gain of function and/or HIF- $2 \alpha$ loss of function). ${ }^{14}$ Although this mouse model exhibits a severe phenotype, it is a daunting task to test therapeutic interventions in the $E g \ln 1^{-/-}$mouse because of the spontaneous and permanent nature of the genetic manipulation. However, hematopoietic cell-derived, PHD2-containing microparticles may be a good place to start. Nevertheless, this mouse model of PAH may be one of the best animal models that captures the progressive and severe late stage of PAH observed in humans.

\section{$\mathrm{KO}^{\mathrm{ITSN}+/-}$ Mice Transduced with $\mathrm{EH}_{\mathrm{ITSN}}$}

Recently, a novel two-hit model was generated on the basis that human PAH patients exhibit diminished levels of intersectin (ITSN)-1 short isoform and express the Epsin15homology domain fragment of ITSN $\left(\mathrm{EH}_{\mathrm{ITSN}}\right)$ : a presumed mechanism reliant on granzyme B secretion by inflammatory T cells. ${ }^{45}$ Perivascular inflammatory cell infiltrates have been well defined in human PAH disease. ${ }^{37,46,47}$ Furthermore, using the classic MCT model, it has been shown that $\mathrm{CD} 8^{+} \mathrm{T}$ cells are up-regulated in MCT-treated rat lungs compared with control rat lungs, ${ }^{48}$ suggesting a role of $\mathrm{CD} 8^{+} \mathrm{T}$ cells in the first phase of PAH. Moreover, previous studies provide evidence that $\mathrm{CD} 8^{+} \mathrm{T}$ cells are attracted to PLs in the late-stage disease. ${ }^{37,46,47} \mathrm{CD}^{+} \mathrm{T}$ cells secrete granzyme B, which can cleave ITSN, resulting in the loss of the prosurvival signaling cascade of full-length ITSN; this induces an initial apoptotic event that is later reconciled by prolonged proliferative signaling in ECs, driven by the granzyme $\mathrm{B}-$ generated $\mathrm{EH}_{\text {ITSN }}$ cleavage fragment. ${ }^{45,49}$ The $\mathrm{EH}_{\text {ITSN }}$ fragment induces prolonged proliferation in ECs by a p38 MAPK-dependent signaling cascade, resulting in Elk1 transcription factor and c-Fos immediate early response gene activation. ${ }^{45}$ Taking these findings one step further, this mechanism was recreated in a mouse model resembling ITSN deficiency, through genetic manipulation [ITSN knockout heterozygous $\left(\mathrm{KO}^{I T S N+/-}\right)$ mice], and $\mathrm{EH}_{\text {ITSN }}$ expression via cationic liposome delivery of plasmid DNA containing the $\mathrm{EH}_{\text {ITSN }}$ fragment. Intriguingly, after 10 retro-orbital injections of $\mathrm{EH}_{\mathrm{ITSN}}$-containing lipoplexes into mouse lungs over a 20-day period, significant pulmonary remodeling occurs. Surprisingly, the $\mathrm{EH}_{\text {ITSN }}$ proliferative potential was not just specific to ECs, and it induced smooth muscle cell proliferation. ${ }^{50}$ Furthermore, fibroblast proliferation was evident, and led to adventitial thickening; in some cases, media-fibroproliferative structures were identified within the vessel wall and, therefore, led to significant increases in vessel wall thickness. ${ }^{50}$ Moreover, a plethora of EC-driven vascular arteriopathy is observed in this mouse model, including subtotal and complete concentric onion-skin-like intima thickening, eccentric intima proliferation, EC hobnail patterns, obliterative lesions with vascular slit-like channels, stalk-like lesions within the vessel lumen, peribronchial and subpleural lesions, and complex plexiform-like lesions. ${ }^{50}$ Furthermore, this model also exhibits distal extension of smooth muscle into the small- to medium-sized pulmonary arteries, 
collagen deposition, and inflammatory cell infiltrates, characterized by a high nuclear/cytosol ratio. ${ }^{50}$ Surprisingly, despite the extensive angio-obliterative remodeling present in the EH-KO ${ }^{I T S N+/-}$ mice, only a modest increase in RVSP and RVH was observed. ${ }^{50}$ However, the mice used in this study were all young female mice; it is generally accepted that older male mice exhibit a more severe hemodynamic phenotype. In addition, these mice underwent a 20-day treatment regimen, during which right ventricular adaptations occur after prolonged lung remodeling. Nevertheless, to our knowledge, this mouse model is the first model to develop significant pulmonary remodeling without targeting molecular players implicated in hypoxia-induced pulmonary hypertension. This provides a significant advantage over other animal models, as it may use pathophysiological mechanisms pertinent to cases of idiopathic $\mathrm{PAH}$, a disease in which the molecular mechanisms driving the pathology are still not well known.

\section{Relevance of PAH Animal Models to PAH in Humans}

Histologic studies in the human lung suggest that two key phases exist in the pathogenesis of PAH. The first is defined by a so-called nonspecific medial and adventitial thickening of the pulmonary artery, distal extension of smooth muscle to the normally nonmuscularized small pulmonary arteries, and an aberrant inflammatory cell response. ${ }^{8}$ This initial phase is apparent in the classic models of $\mathrm{PH}$; however, hypoxia-induced $\mathrm{PH}$ tends to halt at this stage and does not progress to the second stage (ie, nonspecific and smallarteriole muscularization of the pulmonary artery is evident, but a complex remodeling process does not follow). ${ }^{12}$ Furthermore, prolonged hypoxia evokes monocyte and dendritic inflammatory cell infiltration, but not T-cell infiltrates, as observed in the human disease. ${ }^{46,51}$ On the contrary, the MCT lung injury model seems to progress slightly further than the hypoxia-induced pulmonary hypertension model, but still, it does not truly resemble severe plexogenic arteriopathy observed in humans. The MCT model induces distal muscularization of the pulmonary artery, in addition to an elaborate inflammatory response, likely attributed to its widespread pneumotoxicity. ${ }^{17}$ However, plexogenic arteriopathy is lacking in this model. Therefore, the classic models only seem to capture the first phase of PAH, and not the second. Similar to the classic models, the administration of Su5416 in conjunction with hypoxic stress-but lacking a normoxic recovery period-results in extensive muscularization and a severe pulmonary hypertension phenotype, but not the extensive remodeling process associated with the second phase of PAH. ${ }^{30}$

After the first phase of PAH is a progressive remodeling process, or second phase, characterized by a proliferative multicellular milieu, resulting in neointimal, plexiform, and angio-obliterative lesions that occlude small- and mediumsized pulmonary arteries; thereby, they restrict blood flow and, hence, limit the delivery of nutrients. ${ }^{8}$ Contrary to the $\mathrm{Su}$ $\mathrm{Hx}$ model, the Su-Hx-Nx rat model recapitulates not only the first phase, but also the second phase, seen in the human PAH disease. In this rat model, three types of plexogenic arteriopathy were recreated and are defined as concentric laminar neointimal, stalk-like, and aneurysm-like complex lesions. ${ }^{31}$ These three types of lesions are extremely similar to the severe PLs that develop during late-stage PAH in humans. ${ }^{52}$ Furthermore, these rats developed significant increases in pulmonary blood pressure and RVH. ${ }^{31}$ However, these changes incurred before returning the rats to a normoxic environment, and, therefore, this phenotype is likely attributable to an additive effect of Su5416 and hypoxia, ${ }^{30}$ not the severe remodeling process that ensues after normoxic return. ${ }^{31}$ Nevertheless, this rat model set the bar that newly developed rodent models designed to study PAH must strive for. The IL-6-overexpressing mouse, as a single-hit stimulus (ie, genetic predisposition), mimics the first phase of PAH; however, without hypoxic stress, the IL- $6 \mathrm{Tg}^{+}$mice do not exhibit severe features of the complex plexiform-like lesions, as observed in humans. ${ }^{36}$ Although these pathologic features are exacerbated by hypoxic stress, thereby qualifying as a two-hit model, the resultant plexogenic arteriopathy in the IL$6 \mathrm{Tg}^{+}-\mathrm{Hx}$ mice does not compare with the $E g \ln 1^{-/-}$or the $\mathrm{EH}-\mathrm{KO}^{I T S N+/-}$ mouse models. The $E g \ln 1^{-/-}$mouse model, to our knowledge, best recapitulates heart dysfunction associated with PAH in humans, whereas the EH-KO ${ }^{I T S N+/-}$ mouse best resembles plexogenic arteriopathy observed in human PAH lung samples. The Egln ${ }^{-1-}$ mouse exhibits severe increases in RVSP and RVH, as shown by hemodynamic measurements, echocardiogram, and the Fulton index, with both parameters being strongly implicated in the human disease. ${ }^{6,15}$ Furthermore, the Egln $1^{-1-}$ mouse demonstrates an elaborate remodeling process in the lung, with the formation of complex plexiform-like lesions and concentric occlusive neointimal lesions with slit-like channels. ${ }^{15}$ However, this mouse model does not seem to capture the wide array of vasculopathy observed in human $\mathrm{PAH}^{53}$ and that observed in the EH-KO ${ }^{I T S N+/-}$ mouse model. In the EH$\mathrm{KO}^{I T S N+/-}$ mouse, a significant amount of plexiform-like structures are present. In fact, aside from capturing the primary phase of $\mathrm{PAH}$, this mouse model goes above and beyond the expectations needed to qualify for a preclinical model of plexogenic arteriopathy. First, this mouse model was developed on the basis that T-cell ${ }^{45,46,50}$ infiltrates are present in the lung during the initial inflammatory event that stimulates PAH pathogenesis. This is the first animal model, to our knowledge, to simulate PAH pathogenesis from onset to late-stage disease (ie, inflammation attributable to EC dysfunction $\rightarrow$ aberrant cellular proliferation/complex plexogenic arteriopathy). Second, this mouse model exhibits extensive perivascular/peribronchial edema that is evident in the human disease. ${ }^{6,53}$ Moreover, the EH-KO ${ }^{I T S N+/-}$ mouse portrays a wide variety of pathogenic structures and lesions, 


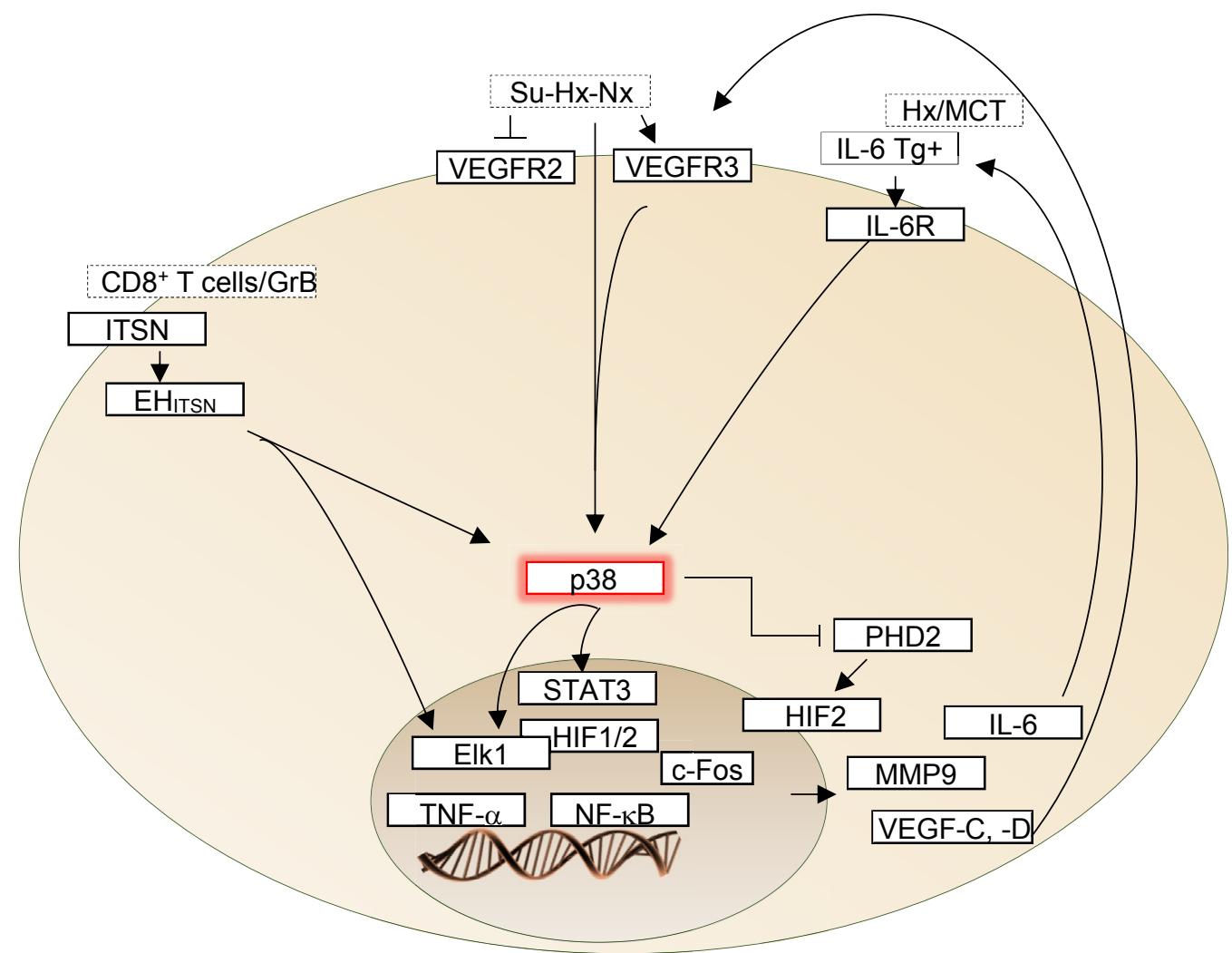

Figure 1 Signaling pathways that converge on p38 mitogen-activated protein kinase (MAPK) activation and formation of plexiform-like lesions in pulmonary arterial hypertension (PAH). In both hypoxia $(\mathrm{Hx})$ and monocrotaline (MCT) animal models and in human disease, p38 MAPK signaling through IL-6 provides a link between vascular remodeling and inflammation. IL-6 activates STAT3 in a process dependent on serine phosphorylation by p38 kinase and tyrosine phosphorylation by Src. STAT3 activation in both human and experimental models of PAH accounts for the modulation of the expression of several proteins implicated in PAH pathogenesis. ${ }^{61}$ Protein components of the vascular endothelial growth factor (VEGF) signaling pathway have been implicated as potential biomarkers in experimental models and human PAH; however, the signaling pathways involved are not clear. Interestingly, in cancer cells, a link between VEGF receptor (VEGFR) and p38 kinase has been reported. ${ }^{62,63}$ VEGF, acting through its receptor, activates p38 MAPK; and induces expression of erythroblast transformation-specific 1 (ETS1), an important trans regulator of matrix metallopeptidase (MMP) genes, including MMP9. During hypoxia, activation of p38 MAPK signaling is likely to prevent prolyl hydroxylase domain proteins (PHDs) from hydroxylating proline residues of hypoxia-inducible factor

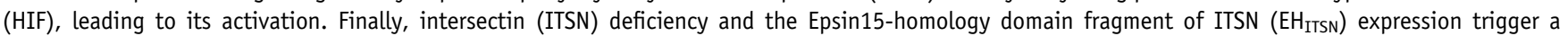
pathogenic p38 MAPK/Elk1 signaling pathway, leading to plexiform lesion formation in severe PAH. As $\mathrm{EH}_{\text {ITSN }}$ localizes to the nucleus, ${ }^{64}$ a direct effect on transcription factors cannot be ruled out. GrB, granzyme B; Su-Hx-Nx, a model in which, after a single injection of Sugen5416 and 3 weeks of hypobaric $\mathrm{Hx}$, the rats were returned to normoxia for 10 to 11 weeks; Tg, transgenic; TNF- $\alpha$, tumor necrosis factor- $\alpha$.

including media-fibroproliferation, that lead to increases in vessel wall thickness, concentric laminar neointimal lesions, aneurysm-like complex lesions, stalk-like lesions, complex plexiform-like lesions, EC hobnail patterns, occlusive lesions with slit-like EC channels, and peribronchial and subpleural lesions. ${ }^{50}$ Of course, both the $E g \ln 1^{-1-}$ and EH-KO $\mathrm{K}^{I T S N+/-}$ mouse models recapitulate the first phase of the disease, as this is the preliminary step in PAH pathogenesis and thereby precedes the progressive phase of the disease (ie, plexogenic arteriopathy).

\section{Toward a Converging Mechanism for PLs Formation}

The cellular composition of PLs has not conclusively been determined. PLs are thought to involve the cross talk between quiescent ECs lining the dynamic network of vascular channels and proliferating, apoptosis-resistant ECs, apoptosis-resistant myofibroblasts, smooth muscle cells, or even undifferentiated mesenchymal cells at the core of the lesion. $^{54,55}$ The animal models of plexiform PAH demonstrate that rats treated simultaneously with MCT and hypoxia develop plexiform-like lesions. ${ }^{28}$ Furthermore, rats subjected to surgical pneumonectomy, followed by a 1-week recovery period, during which the rats are given a single dose of MCT, develop complex plexiform-like lesions. ${ }^{29}$ A single injection of Su5416, followed by 3 weeks of hypobaric hypoxia and 10 weeks of normoxia, results in the formation of severe PLs. ${ }^{31}$ In mice, IL-6 overexpression, Egln1 KO, and ITSN deficiency, associated with the expression of a granzyme B cleavage fragment of ITSN, were sufficient to induce severe pulmonary arteriopathy, including PLs. ${ }^{15,36,50}$ The molecular mechanisms responsible for the development of PLs are not well understood. Whether PLs share a common molecular pathophysiological mechanism is not known. The molecular 
Table 1 Comparison of Experimental Models of PAH with Respect to Vascular Occlusion, Plexiform-Like Lesion Formation, and Signaling Molecules/Pathways Involved

\begin{tabular}{|c|c|c|c|c|c|c|}
\hline Stimuli & Animal/strain & Pulmonary arteriopathy & $\begin{array}{l}\text { Signaling molecules/ } \\
\text { pathways involved }\end{array}$ & $\begin{array}{l}\text { RVSP, } \\
\mathrm{mmHg}\end{array}$ & $\mathrm{RV} / \mathrm{LV}+\mathrm{S}$ & References \\
\hline $\mathrm{MCT}+\mathrm{Hx}$ & Rat/Wistar & $\begin{array}{l}\text { Concentric and } \\
\text { occlusive }\end{array}$ & $\begin{array}{l}\text { IL- } 6 \text { or TNF- } \alpha, \text { TGF- } \beta \text {, } \\
\text { p38 MAPK, NF- } \kappa B \text {, } \\
\text { HIF- } 1 \alpha\end{array}$ & 70 & 0.54 & $28,56,79$ \\
\hline MCT + pneumonectomy & Rat/Sprague-Dawley & $\begin{array}{l}\text { Plexiform-like lesions } \\
\text { (severe vascular } \\
\text { pruning and } \\
\text { disorganized } \\
\text { vascular networks) }\end{array}$ & & 80 & 1.8 & 29 \\
\hline IL-6 $\mathrm{Tg}^{+}$ & Mouse/C57BL6 & Proliferative & IL-6/STAT, PI3K, p38 & $36-65$ & $0.38-0.68$ & 36,80 \\
\hline $\mathrm{IL}-6 \mathrm{Tg}^{+}+\mathrm{Hx}$ & Mouse/C57BL6 & $\begin{array}{l}\text { arteriopathy } \\
\text { (occlusive } \\
\text { neointimal } \\
\text { angioproliferative } \\
\text { lesions; effects } \\
\text { enhanced by } \\
\text { hypoxia) }\end{array}$ & MAPK, ERK1/2 MAPK & & & \\
\hline Su5416+Hx & Rat/Sprague-Dawley & $\begin{array}{l}\text { Occlusive, EC } \\
\text { expansion }\end{array}$ & ND & 35 & 0.5 & 30 \\
\hline $\mathrm{Su}+\mathrm{Hx}+\mathrm{Nx}$ & Rat/Sprague-Dawley & $\begin{array}{l}\text { Concentric neointimal } \\
\text { and complex } \\
\text { plexiform-like } \\
\text { lesions }\end{array}$ & $\begin{array}{l}\text { p38 MAPK, HIF-1 } \alpha \text {, } \\
\text { VEGFR3 }\end{array}$ & 96 & 0.74 & 31,32 \\
\hline$E g \ln 1^{-/-}$ & Mouse/C57BL6 & $\begin{array}{l}\text { Vascular occlusion and } \\
\text { plexiform-like } \\
\text { lesions }\end{array}$ & PHD2, HIF-2 $\alpha$ & 75 & 0.9 & 15,68 \\
\hline $\mathrm{EH}-\mathrm{KO} \mathrm{O}^{I T S N+/-}$ & Mouse/129SV/J & $\begin{array}{l}\text { Occlusive, complex } \\
\text { plexiform lesions }\end{array}$ & p38 MAPK, Elk1, c-Fos & 26 & 0.27 & 50,68 \\
\hline
\end{tabular}

$\mathrm{EC}$, endothelial cell; $\mathrm{EH}-\mathrm{KO} \mathrm{ITSN}^{\mathrm{ITS}}$, Epsin15-homology domain fragment of intersectin knockout heterozygous; ERK, extracellular signal-regulated kinase; HIF, Hx-inducible factor; Hx, hypoxia; LV, left ventricle; MAPK, mitogen-activated protein kinase; MCT, monocrotaline; ND, not determined; Nx, normoxia; PAH, pulmonary arterial hypertension; PHD, prolyl hydroxylase domain protein; PI3K, phosphatidylinositol 3-kinase; RV, right ventricle; RVSP, right ventricular systolic pressure; Su5416, Sugen5416; Su $+\mathrm{Hx}+\mathrm{Nx}$, a model in which, after a single injection of Sugen5416 and 3 weeks of hypobaric Hx, the rats were returned to normoxia for 10 to 11 weeks; Tg, transgenic; TGF- $\beta$, transforming growth factor- $\beta$; TNF- $\alpha$, tumor necrosis factor- $\alpha$; VEGFR3, vascular endothelial growth factor receptor protein tyrosine kinase 3.

processes driving formation of PLs in experimental models and human disease involve, but are not limited to, p38 MAPK, IL-6/STAT, VEGFRs, PHD2, and downstream activation of erythroblast transformation-specific (ETS), $\mathrm{HIF}$, and NF-KB transcription factors, as well as increased expression of VEGF and matrix metallopeptidase 9. $15,36,40,50,56-63$ The relative significance of any given signaling pathway studied thus far seems to be influenced by the specific animal strain, stimulus, age, sex, environment, or cell type. However, the activation of p38 MAPK appears to be a characteristic of animal models of PAH that develop PLs. This observation suggests that formation of PLs may share a common pathophysiological mechanism that converges on p38 MAPK activation (Figure 1). In rats, specific inhibition of p38 MAPK attenuates vascular proliferation in the MCT-induced PAH. ${ }^{56}$ Church et $\mathrm{al}^{58}$ reported that the p38 MAPK plays a pathogenic role in both human disease and MCT-rodent models of pulmonary hypertension, potentially mediated through IL-6. Furthermore, activation of p38
MAPK has recently been reported in the Su5416 rat model of $\mathrm{PAH}$, suggesting that, in these rats, the activation of $\mathrm{p} 38$ kinase may occur independently of VEGFR2 inhibition and, thus, may help explain the paradox of VEGF receptor blockade-induced pulmonary hypertension that characterizes the Su-Hx rat model of PAH. ${ }^{65,66}$ Another important observation is that the stabilization of HIF proteins is primarily regulated by hydroxylation of proline residues by $\mathrm{PHDs}^{59}$ and that the p38 MAPK is a key component of hypoxic response pathways. ${ }^{67}$ During hypoxia, activation of p38 MAPK signaling is likely to prevent PHDs from hydroxylating proline residues of HIF, an observation that leads us to the Egln1 (encoding PHD2) KO mouse model of PAH. HIF$2 \alpha$ activation, downstream of PHD2 deficiency, mediates the severe lung plexiform phenotype of the Eglnl-deficient mouse. ${ }^{15}$ It seems that HIF-2 activation, as caused by either p38 MAPK activation or PHD2 deficiency, results in PLs.

Moreover, signaling pathways activated in animal models of plexiform $\mathrm{PAH}$ include, but are not limited to, small 
GTPases, phosphatidylinositol 3-kinase/Akt, protein kinase $\mathrm{C} \zeta$, protein kinase $\mathrm{A}$, transforming growth factor- $\beta$, STAT, Elk1, and c-Fos. Many of these signal transduction molecules can activate the p38 MAPK signaling pathway. Moreover, p38 kinase regulates downstream targets, including several kinases, transcription factors, and cytosolic proteins, to orchestrate several regulatory mechanisms in many cellular responses, like cell survival and proliferation. In PAH settings, an important transcription factor phosphorylated by p38 is Elk1, a member of the ETS family of transcription factors. Elk1 works in concert with HIF-2 to cooperatively activate HIF-2 target genes. ${ }^{50,68}$ Moreover, Elk1 is an important link between hypoxia, c-Fos, and c-Fos target genes, such as matrix metalloproteases that play a crucial role in the development of PAH. ${ }^{69,70}$ These findings suggest that the p38 MAPK/Elk1/HIF-2 $\alpha$ signaling axis is central to PL formation in PAH. Moreover, increased expression of phosphorylated p38 MAPK was observed in the pulmonary vasculature from patients with idiopathic PAH. ${ }^{45,58}$ Furthermore, ITSN deficiency and expression of the $\mathrm{EH}_{\text {ITSN }}$ fragment have been detected in the lung tissue of human PAH patients. ${ }^{45}$ As $\mathrm{EH}_{\mathrm{ITSN}}$ localizes to the nucleus, ${ }^{64}$ a direct effect on transcription factors cannot be ruled out.

Studies have shown that IL-6 is elevated in the serum and lungs of patients with $\mathrm{PAH}^{38,71}$ On further investigation, increased levels of IL-6 associate with poor prognosis of patients with idiopathic and familial PAH. ${ }^{72}$ Moreover, VEGF and VEGFR-2 are overexpressed in the PLs of patients with PAH, ${ }^{73}$ and plasma VEGF levels are elevated in patients with idiopathic PAH. ${ }^{74}$ Interestingly, a significant decrease in VEGFR3 expression in pulmonary artery ECs from human PAH subjects has recently been reported. ${ }^{75}$ The convergence between the bone morphogenetic protein and VEGF signaling pathways is through a novel interaction between VEGFR3 and bone morphogenetic protein type II receptor; bone morphogenetic protein type II receptor mutations, underlying familial $\mathrm{PAH}$, demonstrate a gain of function involving up-regulation of $\mathrm{p} 38^{\mathrm{MAPK}}$-dependent proproliferative pathways. ${ }^{76}$ These interactions further support $\mathrm{p} 38$ kinase as a central molecular mediator of PL formation. Pulmonary hypertension is at least, in part, HIF2 $\alpha$ dependent. ${ }^{15,77}$ Tumor necrosis factor- $\alpha$ also appears to play a role in PAH as circulating levels of tumor necrosis factor- $\alpha$ are increased in PAH patients. ${ }^{71,72,78,79}$ Activation of STAT3 mediates the hyperproliferation and apoptosis resistance of ECs in PAH lungs and, therefore, may also play a role in PL development. ${ }^{80}$ A comparison of experimental models of PAH with respect to vascular occlusion, plexiform-like lesion formation, and signaling molecules/pathways involved is shown in Table 1 . Although caution is necessary for extrapolating the findings of animal research to the care of human disease, these observations may help to solve the complex puzzle of plexiform arteriopathy.

\section{Conclusion}

PAH remains a severe and overwhelmingly morbid disease, with 5-year survival rates averaging $<60 \%$. $^{2,5,7}$ With today's technology, public demand for better PAH therapeutics is well warranted, but science has yet to provide an answer in regard to better treatment options. Perhaps, this is because of insufficient means to study the disease itself (ie, inappropriate animal models). Over many years, numerous rodent models were developed in efforts to improve our means to study this dreadful disease. ${ }^{81}$ However, many failed to answer our calls, and, thus, survival rates remain low. The classic rodent models, such as hypoxia-induced pulmonary hypertension and MCT-induced pulmonary hypertension, only recapitulate the first phase of the disease and, therefore, led to development of drugs targeting the process of vasoconstriction rather than those that target the progressive, remodeling phase of PAH. The recent emergence of two-hit animal models has tremendously improved our understanding of the pathogenesis and pathobiological mechanisms through which PAH progresses. The two-hit models, the Su-Hx-Nx rat model, the IL-6 $\mathrm{Tg}^{+} /$hypoxia mouse model, and the Egln $1^{-1-}$ mouse model-endothelial and hematopoietic cell specific (hence, two-hit models) and the EH-KO ${ }^{I T S N+/-}$ mouse model have provided a newfound hope for researchers in the field: the progressive part of PAH can now be studied intensely. Moreover, these models appear particularly useful when focusing on the p38 MAPK signaling pathway and its emerging role in mediating cellular cross talk between the vasculature and inflammatory cells within PLs. Understanding these connections will aid in designing new and more effective approaches for PAH treatment.

As research continues and treatment standards improve, discovering therapeutic cocktails to alter the signaling cascades affected during the progressive phase of the disease will be necessary. Time will tell, but it is hopeful that this terrible disease will no longer remain so grim and outcomes will move forward and improve, as did our modeling system of the disease.

\section{References}

1. McGonigle P, Ruggeri B: Animal models of human disease: challenges in enabling translation. Biochem Pharmacol 2014, 87 $162-171$

2. Benza RL, Miller DP, Barst RJ, Badesch DB, Frost AE, McGoon MD: An evaluation of long-term survival from time of diagnosis in pulmonary arterial hypertension from the REVEAL Registry. Chest 2012, 142:448-456

3. Rabinovitch M, Guignabert C, Humbert M, Nicolls MR: Inflammation and immunity in the pathogenesis of pulmonary arterial hypertension. Circ Res 2014, 115:165-175

4. Tuder RM: Pulmonary vascular remodeling in pulmonary hypertension. Cell Tissue Res 2017, 367:643-649

5. Humbert M, Sitbon O, Chaouat A, Bertocchi M, Habib G, Gressin V, Yaici A, Weitzenblum E, Cordier JF, Chabot F, Dromer C, Pison C, Reynaud-Gaubert M, Haloun A, Laurent M, Hachulla E, Cottin V, 
Degano B, Jais X, Montani D, Souza R, Simonneau G: Survival in patients with idiopathic, familial, and anorexigen-associated pulmonary arterial hypertension in the modern management era. Circulation 2010, 122:156-163

6. Thenappan T, Ormiston ML, Ryan JJ, Archer SL: Pulmonary arterial hypertension: pathogenesis and clinical management. BMJ 2018, 360:j5492

7. Ahmed S, Palevsky HI: Pulmonary arterial hypertension related to connective tissue disease: a review. Rheum Dis Clin North Am 2014, 40:103-124

8. Stenmark KR, Meyrick B, Galie N, Mooi WJ, McMurtry IF: Animal models of pulmonary arterial hypertension: the hope for etiological discovery and pharmacological cure. Am J Physiol Lung Cell Mol Physiol 2009, 297:L1013-L1032

9. Grover RF: Pulmonary circulation in animals and man at high altitude. Ann N Y Acad Sci 1965, 127:632-639

10. He LS, Chang SW, Voelkel NF: Pulmonary vascular reactivity in Fischer rats. J Appl Physiol 1991, 70:1861-1866

11. Sato K, Webb S, Tucker A, Rabinovitch M, O'Brien RF, McMurtry IF, Stelzner TJ: Factors influencing the idiopathic development of pulmonary hypertension in the fawn hooded rat. Am Rev Respir Dis 1992, 145:793-797

12. Hoshikawa $\mathrm{Y}$, Nana-Sinkam $\mathrm{P}$, Moore MD, Sotto-Santiago $\mathrm{S}$, Phang T, Keith RL, Morris KG, Kondo T, Tuder RM, Voelkel NF, Geraci MW: Hypoxia induces different genes in the lungs of rats compared with mice. Physiol Genomics 2003, 12:209-219

13. Mirrakhimov AE, Strohl KP: High-altitude pulmonary hypertension: an update on disease pathogenesis and management. Open Cardiovasc Med J 2016, 10:19-27

14. Bigham AW, Lee FS: Human high-altitude adaptation: forward genetics meets the HIF pathway. Genes Dev 2014, 28: 2189-2204

15. Dai Z, Li M, Wharton J, Zhu MM, Zhao YY: Prolyl-4 hydroxylase 2 (PHD2) deficiency in endothelial cells and hematopoietic cells induces obliterative vascular remodeling and severe pulmonary arterial hypertension in mice and humans through hypoxia-inducible factor2alpha. Circulation 2016, 133:2447-2458

16. Stegelmeier BL, Edgar JA, Colegate SM, Gardner DR, Schoch TK, Coulombe RA, Molyneux RJ: Pyrrolizidine alkaloid plants, metabolism and toxicity. J Nat Toxins 1999, 8:95-116

17. Gomez-Arroyo JG, Farkas L, Alhussaini AA, Farkas D, Kraskauskas D, Voelkel NF, Bogaard HJ: The monocrotaline model of pulmonary hypertension in perspective. Am J Physiol Lung Cell Mol Physiol 2012, 302:L363-L369

18. Shah M, Patel K, Sehgal PB: Monocrotaline pyrrole-induced endothelial cell megalocytosis involves a Golgi blockade mechanism. Am J Physiol Cell Physiol 2005, 288:C850-C862

19. Hasegawa M, Kapelyukh Y, Tahara H, Seibler J, Rode A, Krueger S, Lee DN, Wolf CR, Scheer N: Quantitative prediction of human pregnane X receptor and cytochrome P450 3A4 mediated drug-drug interaction in a novel multiple humanized mouse line. Mol Pharmacol 2011, 80:518-528

20. Nelson DR, Zeldin DC, Hoffman SM, Maltais LJ, Wain HM, Nebert DW: Comparison of cytochrome P450 (CYP) genes from the mouse and human genomes, including nomenclature recommendations for genes, pseudogenes and alternative-splice variants. Pharmacogenetics 2004, 14:1-18

21. Dumitrascu R, Koebrich S, Dony E, Weissmann N, Savai R, Pullamsetti SS, Ghofrani HA, Samidurai A, Traupe H, Seeger W, Grimminger F, Schermuly RT: Characterization of a murine model of monocrotaline pyrrole-induced acute lung injury. BMC Pulm Med 2008, 8:25

22. Goto J, Ishikawa K, Kawamura K, Watanabe Y, Matumoto H, Sugawara D, Maruyama Y: Heme oxygenase-1 reduces murine monocrotaline-induced pulmonary inflammatory responses and resultant right ventricular overload. Antioxid Redox Signal 2002, 4: $563-568$
23. Wilson DW, Segall HJ, Pan LC, Dunston SK: Progressive inflammatory and structural changes in the pulmonary vasculature of monocrotaline-treated rats. Microvasc Res 1989, 38:57-80

24. Meyrick BO, Reid LM: Crotalaria-induced pulmonary hypertension: uptake of 3H-thymidine by the cells of the pulmonary circulation and alveolar walls. Am J Pathol 1982, 106:84-94

25. Bogaard HJ, Natarajan R, Mizuno S, Abbate A, Chang PJ, Chau VQ, Hoke NN, Kraskauskas D, Kasper M, Salloum FN, Voelkel NF: Adrenergic receptor blockade reverses right heart remodeling and dysfunction in pulmonary hypertensive rats. Am J Respir Crit Care Med 2010, 182:652-660

26. Tuder RM, Abman SH, Braun T, Capron F, Stevens T, Thistlethwaite PA, Haworth SG: Development and pathology of pulmonary hypertension. J Am Coll Cardiol 2009, 54:S3-S9

27. Rabinovitch M: Molecular pathogenesis of pulmonary arterial hypertension. J Clin Invest 2012, 122:4306-4313

28. Morimatsu Y, Sakashita N, Komohara Y, Ohnishi K, Masuda H, Dahan D, Takeya M, Guibert C, Marthan R: Development and characterization of an animal model of severe pulmonary arterial hypertension. J Vasc Res 2012, 49:33-42

29. White RJ, Meoli DF, Swarthout RF, Kallop DY, Galaria II, Harvey JL, Miller CM, Blaxall BC, Hall CM, Pierce RA, Cool CD, Taubman MB: Plexiform-like lesions and increased tissue factor expression in a rat model of severe pulmonary arterial hypertension. Am J Physiol Lung Cell Mol Physiol 2007, 293:L583-L590

30. Taraseviciene-Stewart L, Kasahara Y, Alger L, Hirth P, Mc Mahon G, Waltenberger J, Voelkel NF, Tuder RM: Inhibition of the VEGF receptor 2 combined with chronic hypoxia causes cell deathdependent pulmonary endothelial cell proliferation and severe pulmonary hypertension. FASEB J 2001, 15:427-438

31. Abe K, Toba M, Alzoubi A, Ito M, Fagan KA, Cool CD, Voelkel NF, McMurtry IF, Oka M: Formation of plexiform lesions in experimental severe pulmonary arterial hypertension. Circulation 2010, 121: $2747-2754$

32. Voelkel NF, Gomez-Arroyo J: The role of vascular endothelial growth factor in pulmonary arterial hypertension: the angiogenesis paradox. Am J Respir Cell Mol Biol 2014, 51:474-484

33. Michelakis ED, Wilkins MR, Rabinovitch M: Emerging concepts and translational priorities in pulmonary arterial hypertension. Circulation 2008, 118:1486-1495

34. Lee SD, Shroyer KR, Markham NE, Cool CD, Voelkel NF, Tuder RM: Monoclonal endothelial cell proliferation is present in primary but not secondary pulmonary hypertension. J Clin Invest 1998, 101:927-934

35. Vitali SH, Hansmann G, Rose C, Fernandez-Gonzalez A, Scheid A, Mitsialis SA, Kourembanas S: The Sugen 5416/hypoxia mouse model of pulmonary hypertension revisited: long-term follow-up. Pulm Circ 2014, 4:619-629

36. Steiner MK, Syrkina OL, Kolliputi N, Mark EJ, Hales CA, Waxman AB: Interleukin-6 overexpression induces pulmonary hypertension. Circ Res 2009, 104:236-244. 28p following 244

37. Tuder RM, Groves B, Badesch DB, Voelkel NF: Exuberant endothelial cell growth and elements of inflammation are present in plexiform lesions of pulmonary hypertension. Am J Pathol 1994, 144: 275-285

38. Humbert M, Monti G, Brenot F, Sitbon O, Portier A, GrangeotKeros L, Duroux P, Galanaud P, Simonneau G, Emilie D: Increased interleukin-1 and interleukin-6 serum concentrations in severe primary pulmonary hypertension. Am J Respir Crit Care Med 1995, 151:1628-1631

39. Yoshio T, Masuyama JI, Kohda N, Hirata D, Sato H, Iwamoto M, Mimori A, Takeda A, Minota S, Kano S: Association of interleukin 6 release from endothelial cells and pulmonary hypertension in SLE. J Rheumatol 1997, 24:489-495

40. Pullamsetti SS, Seeger W, Savai R: Classical IL-6 signaling: a promising therapeutic target for pulmonary arterial hypertension. J Clin Invest 2018, 128:1720-1723 
41. Said SI, Hamidi SA, Gonzalez Bosc L: Asthma and pulmonary arterial hypertension: do they share a key mechanism of pathogenesis? Eur Respir J 2010, 35:730-734

42. Greenway S, van Suylen RJ, Du Marchie Sarvaas G, Kwan E, Ambartsumian N, Lukanidin E, Rabinovitch M: S100A4/Mts1 produces murine pulmonary artery changes resembling plexogenic arteriopathy and is increased in human plexogenic arteriopathy. Am J Pathol 2004, 164:253-262

43. Bardita C, Predescu DN, Sha F, Patel M, Balaji G, Predescu SA: Endocytic deficiency induced by ITSN-1s knockdown alters the Smad2/3-Erk1/2 signaling balance downstream of Alk5. J Cell Sci 2015, 128:1528-1541

44. Shah T, Qin S, Vashi M, Predescu DN, Jeganathan N, Bardita C, Ganesh B, diBartolo S, Fogg LF, Balk RA, Predescu SA: Alk5/Runx1 signaling mediated by extracellular vesicles promotes vascular repair in acute respiratory distress syndrome. Clin Transl Med 2018, 7:19

45. Patel M, Predescu D, Tandon R, Bardita C, Pogoriler J, Bhorade S, Wang M, Comhair S, Hemnes AR, Chen J, Machado R, Husain A, Erzurum S, Predescu S: A novel p38 mitogen-activated protein kinase/Elk-1 transcription factor-dependent molecular mechanism underlying abnormal endothelial cell proliferation in plexogenic pulmonary arterial hypertension. J Biol Chem 2013, 288: 25701-25716

46. Savai R, Pullamsetti SS, Kolbe J, Bieniek E, Voswinckel R, Fink L, Scheed A, Ritter C, Dahal BK, Vater A, Klussmann S, Ghofrani HA, Weissmann N, Klepetko W, Banat GA, Seeger W, Grimminger F, Schermuly RT: Immune and inflammatory cell involvement in the pathology of idiopathic pulmonary arterial hypertension. Am J Respir Crit Care Med 2012, 186:897-908

47. Ars C, Thurion P, Delos M, Sibille Y, Pilette C: Small airway obstruction in severe pulmonary arterial hypertension correlates with increased airway CD8+ T-cells and fractalkine expression. Eur Respir J 2009, 34:1494-1496

48. Wang W, Wang YL, Chen XY, Li YT, Hao W, Jin YP, Han B: Dexamethasone attenuates development of monocrotaline-induced pulmonary arterial hypertension. Mol Biol Rep 2011, 38: 3277-3284

49. Loeb CR, Harris JL, Craik CS: Granzyme B proteolyzes receptors important to proliferation and survival, tipping the balance toward apoptosis. J Biol Chem 2006, 281:28326-28335

50. Patel M, Predescu D, Bardita C, Chen J, Jeganathan N, Pritchard M, DiBartolo S, Machado R, Predescu S: Modulation of intersectin-1s lung expression induces obliterative remodeling and severe plexiform arteriopathy in the murine pulmonary vascular bed. Am J Pathol 2017, 187:528-542

51. Burke DL, Frid MG, Kunrath CL, Karoor V, Anwar A, Wagner BD, Strassheim D, Stenmark KR: Sustained hypoxia promotes the development of a pulmonary artery-specific chronic inflammatory microenvironment. Am J Physiol Lung Cell Mol Physiol 2009, 297: L238-L250

52. Pietra GG, Capron F, Stewart S, Leone O, Humbert M, Robbins IM, Reid LM, Tuder RM: Pathologic assessment of vasculopathies in pulmonary hypertension. J Am Coll Cardiol 2004, 43:25S-32S

53. Dorfmuller P, Humbert M, Capron F, Muller KM: Pathology and aspects of pathogenesis in pulmonary arterial hypertension. Sarcoidosis Vasc Diffuse Lung Dis 2003, 20:9-19

54. Cool CD, Stewart JS, Werahera P, Miller GJ, Williams RL, Voelkel NF, Tuder RM: Three-dimensional reconstruction of pulmonary arteries in plexiform pulmonary hypertension using cellspecific markers: evidence for a dynamic and heterogeneous process of pulmonary endothelial cell growth. Am J Pathol 1999, 155: $411-419$

55. St Croix CM, Steinhorn RH: New thoughts about the origin of plexiform lesions. Am J Respir Crit Care Med 2016, 193:484-485

56. Lu J, Shimpo H, Shimamoto A, Chong AJ, Hampton CR, Spring DJ, Yada M, Takao M, Onoda K, Yada I, Pohlman TH, Verrier ED:
Specific inhibition of p38 mitogen-activated protein kinase with FR167653 attenuates vascular proliferation in monocrotaline-induced pulmonary hypertension in rats. J Thorac Cardiovasc Surg 2004, 128: $850-859$

57. Gao L, Liu J, Hao Y, Zhao Z, Tan H, Zhang J, Meng N, Zheng Q, Wang Z, Zhang Y: Chronic intermittent hypobaric hypoxia attenuates monocrotaline-induced pulmonary arterial hypertension via modulating inflammation and suppressing NF-kappaB/p38 pathway. Iran J Basic Med Sci 2018, 21:244-252

58. Church AC, Martin DH, Wadsworth R, Bryson G, Fisher AJ, Welsh DJ, Peacock AJ: The reversal of pulmonary vascular remodeling through inhibition of p38 MAPK-alpha: a potential novel antiinflammatory strategy in pulmonary hypertension. Am J Physiol Lung Cell Mol Physiol 2015, 309:L333-L347

59. Emerling BM, Platanias LC, Black E, Nebreda AR, Davis RJ, Chandel NS: Mitochondrial reactive oxygen species activation of p38 mitogen-activated protein kinase is required for hypoxia signaling. Mol Cell Biol 2005, 25:4853-4862

60. George J, D'Armiento J: Transgenic expression of human matrix metalloproteinase- 9 augments monocrotaline-induced pulmonary arterial hypertension in mice. J Hypertens 2011, 29:299-308

61. Paulin R, Meloche J, Bonnet S: STAT3 signaling in pulmonary arterial hypertension. JAKSTAT 2012, 1:223-233

62. Aesoy R, Sanchez BC, Norum JH, Lewensohn R, Viktorsson K, Linderholm B: An autocrine VEGF/VEGFR2 and p38 signaling loop confers resistance to 4-hydroxytamoxifen in MCF-7 breast cancer cells. Mol Cancer Res 2008, 6:1630-1638

63. Ghosh S, Basu M, Roy SS: ETS-1 protein regulates vascular endothelial growth factor-induced matrix metalloproteinase-9 and matrix metalloproteinase-13 expression in human ovarian carcinoma cell line SKOV-3. J Biol Chem 2012, 287:15001-15015

64. Predescu D, Qin S, Patel M, Bardita C, Bhalli R, Predescu S: Epsin15 homology domains: role in the pathogenesis of pulmonary arterial hypertension. Front Physiol 2018, 9:1393

65. Rafikova O, Williams ER, McBride ML, Zemskova M, Srivastava A, Nair V, Desai AA, Langlais PR, Zemskov E, Simon M, Mandarino LJ, Rafikov R: Hemolysis-induced lung vascular leakage contributes to the development of pulmonary hypertension. Am J Respir Cell Mol Biol 2018, 59:334-345

66. Neto-Neves EM, Frump AL, Vayl A, Kline JA, Lahm T: Isolated heart model demonstrates evidence of contractile and diastolic dysfunction in right ventricles from rats with sugen/hypoxia-induced pulmonary hypertension. Physiol Rep 2017, 5:e13438

67. Park EC, Rongo C: The p38 MAP kinase pathway modulates the hypoxia response and glutamate receptor trafficking in aging neurons. Elife 2016, 5:e12010

68. Pawlus MR, Hu CJ: Enhanceosomes as integrators of hypoxia inducible factor (HIF) and other transcription factors in the hypoxic transcriptional response. Cell Signal 2013, 25:1895-1903

69. Chelladurai P, Seeger W, Pullamsetti SS: Matrix metalloproteinases and their inhibitors in pulmonary hypertension. Eur Respir J 2012, 40:766-782

70. Muller JM, Krauss B, Kaltschmidt C, Baeuerle PA, Rupec RA: Hypoxia induces c-fos transcription via a mitogen-activated protein kinase-dependent pathway. J Biol Chem 1997, 272: 23435-23439

71. Kylhammar D, Hesselstrand R, Nielsen S, Scheele C, Radegran G: Angiogenic and inflammatory biomarkers for screening and followup in patients with pulmonary arterial hypertension. Scand J Rheumatol 2018, 47:319-324

72. Soon E, Holmes AM, Treacy CM, Doughty NJ, Southgate L, Machado RD, Trembath RC, Jennings S, Barker L, Nicklin P, Walker C, Budd DC, Pepke-Zaba J, Morrell NW: Elevated levels of inflammatory cytokines predict survival in idiopathic and familial pulmonary arterial hypertension. Circulation 2010, 122:920-927

73. Tuder RM, Chacon M, Alger L, Wang J, Taraseviciene-Stewart L, Kasahara Y, Cool CD, Bishop AE, Geraci M, Semenza GL, 
Yacoub M, Polak JM, Voelkel NF: Expression of angiogenesisrelated molecules in plexiform lesions in severe pulmonary hypertension: evidence for a process of disordered angiogenesis. J Pathol 2001, 195:367-374

74. Sundaram N, Tailor A, Mendelsohn L, Wansapura J, Wang X, Higashimoto T, Pauciulo MW, Gottliebson W, Kalra VK, Nichols WC, Kato GJ, Malik P: High levels of placenta growth factor in sickle cell disease promote pulmonary hypertension. Blood 2010, 116:109-112

75. Hwangbo C, Lee HW, Kang H, Ju H, Wiley DS, Papangeli I, Han J, Kim JD, Dunworth WP, Hu X, Lee S, El-Hely O, Sofer A, Pak B, Peterson L, Comhair S, Hwang EM, Park JY, Thomas JL, Bautch VL, Erzurum SC, Chun HJ, Jin SW: Modulation of endothelial bone morphogenetic protein receptor type 2 activity by vascular endothelial growth factor receptor 3 in pulmonary arterial hypertension. Circulation 2017, 135:2288-2298

76. Rudarakanchana N, Flanagan JA, Chen H, Upton PD, Machado R, Patel D, Trembath RC, Morrell NW: Functional analysis of bone morphogenetic protein type II receptor mutations underlying primary pulmonary hypertension. Hum Mol Genet 2002, 11: $1517-1525$
77. Formenti F, Beer PA, Croft QP, Dorrington KL, Gale DP, Lappin TR, Lucas GS, Maher ER, Maxwell PH, McMullin MF, O'Connor DF, Percy MJ, Pugh CW, Ratcliffe PJ, Smith TG, Talbot NP, Robbins PA: Cardiopulmonary function in two human disorders of the hypoxiainducible factor (HIF) pathway: von Hippel-Lindau disease and HIF2alpha gain-of-function mutation. FASEB J 2011, 25:2001-2011

78. Itoh T, Nagaya N, Ishibashi-Ueda H, Kyotani S, Oya H, Sakamaki F, Kimura H, Nakanishi N: Increased plasma monocyte chemoattractant protein-1 level in idiopathic pulmonary arterial hypertension. Respirology 2006, 11:158-163

79. Nogueira-Ferreira R, Moreira-Goncalves D, Silva AF, Duarte JA, Leite-Moreira A, Ferreira R, Henriques-Coelho T: Exercise preconditioning prevents MCT-induced right ventricle remodeling through the regulation of TNF superfamily cytokines. Int J Cardiol 2016, 203:858-866

80. Xu W, Erzurum SC: Endothelial cell energy metabolism, proliferation, and apoptosis in pulmonary hypertension. Compr Physiol 2011, $1: 357-372$

81. Sztuka K, Jasinska-Stroschein M: Animal models of pulmonary arterial hypertension: a systematic review and meta-analysis of data from 6126 animals. Pharmacol Res 2017, 125:201-214 